
VEROFFENTLICHUNGEN DER

BERLINER HISTORISCHEN KOMMISSION

BEIM FRIEDRICH-MEINECKE-INSTITUT

DER FREIEN UNIVERSITAT BERLIN

BAND 7

(

Walter de Gruyter \& Co.

vormals G. J. Göschen'sche Verlagshandlung

J. Guttentag, Verlagsbuchbandlung - Georg Reimer - Karl J.Trübner - Veit \& Comp.

Berlin 1962 


\section{OT'TO BƯSCH}

\section{MILITARSYSTEM UND SOZIALLEBEN \\ IM ALTEN PREUSSEN}

$1713-1807$

Die Anfänge der sozialen Militarisierung der preußisch-deutschen Gesellschaft

Mit einer Einfübrung von

HANS HERZFELD

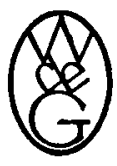

Walter de Gruyter $E$ Co.

vormals G. J. Göschen'sche Verlagshandlung

J.Guttentag, Verlagsbudbhandlung • Georg Reimer - Karl J.Trübner · Veit \& Comp.

Berlin 1962 
(C)

Archiv-Nr. $475962 / 4$

Copyright 1962 by Walter de Gruyter \& Co. - vormals G. J. Göschen'sche Verlagshandlung J. Guttentag, Verlagsbuchhandlung - Georg Reimer - Karl J. Trübner - Veit \& Comp.

Printed in Germany - Alle Rechte der Ubersetzung, des Nachdrucks, der photomechanischen Wiedergabe und der Anfertigung von Mikrofilmen - auch auszugsweise - vorbehalten.

Satz und Druds: Thormann \& Goetsch, Berlin-Neukölln 